\title{
Word and picture identification: Is representational parsimony possible?
}

\author{
KIM KIRSNER, DAN MILECH, and VERONICA STUMPFEL \\ University of Westerm Australia, Perth, Australia
}

\begin{abstract}
Four experiments were conducted to evaluate the proposition that although prior exposure to a printed word facilitates identification of a corresponding picture, exposure to a picture does not facilitate subsequent word recognition (Durso \& Johnson, 1979). Word identification was used, rather than naming latency, in order to avoid the range limitations in adult reading data. Word identification was facilitated by intermodal priming (prior exposure to a corresponding picture), although to a lesser extent than by intramodal (i.e., word-word) priming; the magnitude of intermodal priming was insensitive to strategy; and, as with priming from spoken to printed language, the major impact of word frequency occurred under intermodal, as distinct from intramodal, conditions. Following Scarborough, Gerard, and Cortese (1979), a fifth experiment compared word identification and episodic recognition. Intramodal performance was superior in word identification, whereas intermodal (i.e. picture-word) performance was superior in episodic recognition, a reversal which suggests that episodic recognition involves access to a distinct memory trace.
\end{abstract}

The experiments reported in this paper were conducted to investigate the relationship between the processes involved in the identification of printed words and those involved in the identification of line drawings of objects. The research was motivated by the proposition that identification of printed words, spoken words, and pictures and line drawings of objects involves access to some processes that are common to all of these stimulus classes.

For convenience, we will use the term pictures to refer to line drawings as well as photographic pictures of objects; mode to refer to the contrast between pictures and words (whether spoken or printed); modality to refer to the contrast between spoken and printed words; and stimulus class as a generic term including mode, modality, language, and other form variations.

Our concern is with tasks in which memory effects are recorded incidentally, and our attention is focused on the way in which changes in various attributes influence performance when stimuli are repeated at some interval in a multitrial experiment. This procedure is called repetition priming. In considering the patterns of facilitation, it is now apparent that a qualitative distinction may be made between repetition priming effects and the effects of semantic priming, which occurs between related concepts presented in close temporal proximity. This qualitative distinction is based on two forms of evidence. First, whereas semantic priming effects last, at most, for a few seconds or a few items in a multitrial sequence (Meyer \& Schvaneveldt, 1971), repetition priming yields effects which last for hours or days (Scarborough, Cortese, \&

\footnotetext{
This research was supported by a grant from the Australian Research Grants Scheme. Requests for reprints should be addressed to K. Kirsner, Department of Psychology, University of Western Australia, Perth, Australia 6009. Grateful acknowledgement is made to Roberta Klatzky for her editorial assistance in the preparation of this manuscript.
}

Scarborough, 1977; Tulving, Schacter, \& Stark, 1982). This dissociation is explicit in the findings described by Dannenbring and Briand (1982), Gough, Alford, and Holley-Wilcox (1981) and Henderson, Wallis, and Knight (1984).

The second form of evidence that there is a qualitative distinction between semantic and repetition priming concerns the effects of variations in stimulus class. Whereas repetition priming is reduced or even eliminated by a change in mode (Durso \& Johnson, 1979), modality (Kirsner, Milech, \& Standen, 1983; Kirsner \& Smith, 1974; Morton, 1979) or language (Kirsner, Brown, Abrol, Chaddha, \& Sharma, 1980) of the study and test presentations, semantic priming appears to be insensitive to changes in each of these variables (Kirsner, Smith, Lockhart, King, \& Jain, 1984; Meyer \& Ruddy, 1974; Swinney, Onifer, Prather, \& Hirshkowitz, 1979; Vanderwart, 1984).

One way to characterize this set of results is to contrast priming effects that operate on associative networks, on the one hand, and those that access pathways or units, on the other. Thus, in the case of semantic priming, it is sufficient that (1) a semantically constrained subnetwork of the lexicon is, temporarily, activated, and (2) the network concerned is independent of stimulus class, that is, of mode, modality, and language. Where repetition priming is concerned, however, it appears necessary to posit that processes or units specific to each stimulus class are operating.

In considering the way in which repetition priming is influenced by stimulus class variation, we have developed an account which involves a series of assumptions. The first of these assumptions is that repetition priming reflects changes in the system resulting from processing of an item, changes that facilitate subsequent identification to the extent that the same set of processes are invoked during the study and test presentations. The merit of this as- 
sumption is that it provides a framework within which it is possible to consider the effect of a wide variety of stimulus class and morphological changes.

The second assumption is that in perceptual identification tasks processing can be subdivided into two stages, the first mode- and modality-specific, the second independent of mode and modality. The significance of this assumption is that it provides a means of explaining the selective influence of frequency on the intermodality and, potentially, intermodal components in repetition priming. Whether a variable shows intermodal transfer or differentially affects intramodal and intermodal repetition depends on the stage in which it is represented in the system. Specifically, frequency is a conceptual variable, and therefore occurs in the second (mode- and modality-independent) stage of word identification. Therefore, frequency effects will show no intermodal/intramodal difference.

The third assumption is concerned with task differences. When one goes beyond perceptual identification tasks, to episodic recognition, for example, other processes enter the picture, and very different stimulus class effects may be observed. Specifically, memory judgments often tap associative and imaginal structures that are not used in perceptual identification, and performance under episodic recognition and recall conditions is therefore more susceptible to task and strategy manipulation during acquisition.

The experiments reported below were designed to demonstrate intermodal priming, to examine the equivalence of repetition transfer under intermodal and intermodality conditions, to test specific aspects of the theory by demonstrating that frequency effects are as strong under intermodal as under intramodal conditions, and to contrast perceptual identification and episodic recognition.

\section{EXPERIMENT 1}

The first experiment involved an analysis of repetition priming in word identification. In the first, or study, phase of the experiment, subjects were presented with a mixed sequence of words and line drawings of objects, and were asked to classify each concept as "natural" or "manmade." In the second, or practice, phase, subjects were presented with a sequence of words in which each word was followed by a letter-fragment mask and stimulus onset asynchrony (SOA) was adjusted from trial to trial with a view to establishing the $50 \%$ threshold value for each subject. In the third, or test, phase, subjects were presented with three sets of words at the SOA established during the second phase, and accuracy data was collected under each of three experimental treatments: for words not presented during the study phase (new word treatment), for words presented in the form of line drawings of objects during the study phase (picture-word treatment), and for words presented as words during the study phase (word-word treatment).

The main purpose of the experiment was to reevaluate one arm of the proposition that transfer between pictures and words is asymmetric. According to Durso and John- son (1979), when the test task involves naming, prior exposure to line drawings of the to-be-tested concepts does not yield repetition priming. Using naming latency, Durso and Johnson found significant repetition priming under word-picture conditions (i.e., when the study and test stimuli were words and pictures, respectively). However, they did not find significant transfer under picture-word conditions, a result they attributed to differences in the semantic specificity of words and pictures.

The proposition that repetition transfer between pictures and words is asymmetric requires reassessment for several reasons. The first reason is the prominence given to the alleged asymmetry in theories concerned with picture and word identification processes (Durso \& Johnson, 1979; Morton, 1984; Perecman, 1984). Durso and Johnson, for example, used the presence of asymmetric transfer to argue that picture and word identification involve decomposition and subsequent reference to sets of semantic features. Assuming that words attain access at a more abstract level than do pictures (cf. Jolicoeur, Gluck, \& Kosslyn, 1984), Durso and Johnson argued that words will generally prime pictures, because the semantic features of the latter are a subset of the former, but that pictures will not generally prime words, because the latter depend on a broader range of features. Asymmetric transfer is also built into Morton's (1984) account of the relationship between word processing and picture processing, through his assumption that the output lexicon receives information directly from the visual (print) input logogen system, but not from the equivalent pictorial system.

The second reason stems from our own theoretical position. Specifically, if it can be shown that (1) transfer is symmetric under both intermodal (picture-word and word-picture) and intermodality (spoken word-printed word and printed word-spoken word) conditions, and (2) magnitude of transfer is comparable in all cases, it is appropriate to entertain the hypothesis that a single and therefore parsimonious account can be invoked for the second information-processing stage.

The third reason for reassessment of the proposition is that it depends on data obtained under naming latency conditions, under which the task is highly practiced, and performance may be correspondingly insensitive to repetition effects.

The final reason for reexamination of the proposition is that reanalysis of Durso and Johnson's (1979) data suggests that, when priming is expressed in proportional terms, they found similar repetition transfer under picture-word and word-picture conditions.

In evaluating the impact of stimulus class changes on repetition priming, we have found that it is useful to consider priming in relative, as distinct from absolute, terms (Cristoffanini, Kirsner, Milech, in press; Kirsner, in press; Kirsner \& Dunn, 1985), where relative priming (RP) is defined as

$$
\mathbf{R P}=\text { (alternative form-control) / (same form-control), }
$$

and consideration is restricted to remote repetition conditions (see Kirsner \& Dunn, 1985). The procedure is sub- 
ject to limitations which apply generally to difference data, but it has a number of advantages in the present context. First, it provides a task- and metric-free measure for the analysis of transfer effects, a useful option in a domain where latency, accuracy, and threshold measures are all used in the absence of evidence that they sample mutually exclusive processes. Second, although the inferential conclusions reached in individual studies are masked by the use of RP, the measure provides a basis for descriptive meta-analysis (Hunter, Schmidt, \& Jackson, 1982).

It should be noted, of course, that the equivalence of two RP values does not logically demand the conclusion that the same processes are involved in each case. Inference is restricted to conclusions about the proportion of processes common to the study and test solutions.

The published evidence concerning transfer from pictures to printed words under remote repetition conditions (i.e., the same item is repeated after presentation of at least seven other items) is summarized in Table 1 . Only the semantic classification experiments generally yielded significant transfer. However, it is apparent that pictureword performance was superior to new word performance in each of the nine studies. In particular, when RP is considered, the studies yielded a mean picture-word value of .35 ( $S D=0.22, N=9)$, and, if consideration is further restricted to the naming studies, essentially the same $\mathrm{RP}$ value is obtained: $\mathrm{RP}=0.39(S D=0.19, N=5)$. The equivalent value for transfer from printed words to pictures is 0.47 ( $S D=0.31, N=5$ ); this figure is based on data published by Warren and Morton (1982, Experiment 1) and Durso and Johnson (1979, Experiments 1 and 2).

For comparison, the RP findings for language (between morphologically unrelated translations), modality, speaker's voice, and case are briefly summarized. The RP values observed for these stimulus class variations cover the entire available range. Where language is concerned, the mean RP value over eight combinations of experiment and language treatment is .05 (Cristoffanini et al., in press, Experiment 1, Spanish-English transla- tions; Kirsner et al., 1980, English-Hindi and Hindi-English; Kirsner et al., 1984, Experiments 1 and 3, FrenchEnglish and English-French; Scarborough, Gerard, Cortese, 1984, Experiment 1, Spanish-English). Where modality is concerned, the mean RP value is 0.43 , and there is little difference between transfer from speech to print, where the mean RP value is 0.42 (Clarke \& Morton, 1983, Experiments 2 and 3; Jacoby \& Dallas, 1981, Experiment 6; Kirsner et al., 1983, Experiments 1-8; Kirsner \& Smith, 1974; Monsell, 1985, Experiment 5), and transfer from print to speech, where it is 0.48 (Jackson \& Morton, 1984; Kirsner \& Smith, 1974; Monsell, 1985, Experiment 6). The equivalent RP values for speaker's voice and case are 0.84 (Jackson \& Morton, 1984) and approximately 0.95 (Scarborough et al., 1977), respectively.

In summary, Experiment 1 was designed to determine the presence and the extent of transfer between pictures and words under repetition priming conditions. The following procedural steps were taken in order to obtain suitable data. First, stimulus-limited, as distinct from response-limited, conditions were used in order to overcome problems associated with the use of easy, highly practiced tasks such as naming. Second, a derivative of PEST (Parameter Estimation by Sequential Testing: Pentland, 1980) was used to ensure that subjects were tested at approximately the same level of difficulty, and that the chosen level of difficulty was suitable for an examination of repetition priming effects.

The use of PEST-derived data has several advantages in the present context. Within limits determined by the precision of the data and by the binomial theorem (to reject unsatisfactory solutions), it precludes inclusion of floor and ceiling data that might distort the relative position of an intermediate treatment. In addition, when attention is focused on interactions involving accuracy data (as in Experiments 3 and 4 below), the method can be used to ensure that there is a "crossover interaction" (i.e., a point of intersection) involving the critical functions (Loftus, 1978, p. 315).

Table 1

Absolute and Relative Priming (RP) Values for Picture-Word Transfer as a Function of Experiment, Task, and Task Demand (Stimulus- or Response-Limited)

\begin{tabular}{llccccr}
\hline \multicolumn{1}{c}{ Study } & & \multicolumn{4}{c}{$\begin{array}{c}\text { Repetition Treatment } \\
\text { (Absolute Values) }\end{array}$} \\
\cline { 3 - 7 } & Task-Limit & Notes & NW & PW & WW & RP \\
\hline Durso \& Johnson (1979, Exp. 1) & N-response & ab & & 22 & 35 & .63 \\
Durso \& Johnson (1979, Exp. 2) & N-response & ab & & 6 & 39 & .15 \\
Durso \& Johnson (1979, Exp. 1) & SC-response & ab & & 31 & 76 & .41 \\
Durso \& Johnson (1979, Exp. 2) & SC-response & ab & & 68 & 101 & .67 \\
Durso \& O'Sullivan (1983, Exp. 1) & N-response & cd & 625 & 616 & 695 & .45 \\
Scarborough et al. (1979, Exp. 1) & LD-response & de & 632 & 629 & 598 & .09 \\
Scarborough et al. (1979, Exp. 2) & LD-response & de & 623 & 621 & 601 & .09 \\
Winnick \& Daniel (1970) & WI-stimulus & f & 61.9 & 58.649 .1 & .26 \\
Morton (1979, Exp. 1) & WI-stimulus & f & 123.6 & 118.0111 .0 & .44 \\
\hline
\end{tabular}

Note-NW = new word; PW = picture-word; $W W=$ word-word; $N=$ naming; $S C=$ semantic classification; $L D=$ lexical decision; $\mathrm{WI}=$ word identification. $a$, difference values in milliseconds; $b$, where lag $\geq 8$; $c$, common nouns only; $d$, absolute values in milliseconds; e, estimated from figures; $f$, thresholds in milliseconds. 


\section{Method}

Design. The design involved a single factor, repetition status, with repeated measures on each of three treatments. The treatments were as follows: the new word condition, which consisted of concepts presented, as words, for the first and only time in the test phase of the experiment; the picture-word condition, which consisted of concepts presented as line drawings and as words in the study and test phases of the experiment, respectively; and the wordword condition, which consisted of concepts presented as words in both the study and test phases of the experiment.

Procedure. The experiment was conducted in three phases. The first, or study, phase consisted of a mixed set of 36 words and 36 line drawings of objects. These stimuli were presented item by item for classification as "natural" or "man-made," the task was subject paced, and the subjects were instructed to concentrate on accuracy. The words and line drawings presented in the first phase of the experiment were all presented again, as words, in the test phase of the experiment.

The second phase of the experiment was conducted to give subjects practice with the word identification task and to establish a $50 \%$ threshold SOA value for each subject. The initial set of 10 trials was conducted to provide practice. The stimuli were presented at very long but decreasing SOAs, and the lowest value reached in this series provided the starting value for the parameter estimation trials. There were a maximum of 50 parameter estimation trials. Each trial consisted of a word, followed, after a predetermined SOA. by a mask consisting of letter fragments. The subject's task was to identify the word.

From the perspective of the experimenter, the trials were blocked in groups of five, the SOA was set for each group, and the parameter estimation input from each group was either "correct" or "incorrect," according to the outcome of greater frequency. At the end of each group of trials, the output from each completed group was used to calculate a maximum likelihood estimate of the $50 \%$ point on the distribution of percent correct over SOA. The final estimate was used as the SOA throughout the test phase of the experiment.

From the perspective of the subject, there was no break between the parameter estimation and test phases of the experiment. The stimulus presentation procedure was exactly the same (except that all stimuli were presented at a constant SOA) and the task was unchanged.

The third, or test, phase consisted of 108 words, 36 from the new word condition, 36 from the picture-word condition, and 36 from the word-word condition.

Including instructions for the second phase, the first, second, and third phases of the experiment lasted for approximately 7,10 , and $10 \mathrm{~min}$, respectively. The mean repetition interval was therefore approximately $18.5 \mathrm{~min}$.

Stimulus selection and presentation. One hundred eight concepts were chosen from the standardized set of line drawings described by Snodgrass and Vanderwart (1980). The concepts were selected to meet the following requirements: (1) low word frequency, with a range from 1 to 38 per million (Kucera \& Francis, 1967); (2) high picture naming consistency (greater than $80 \%$ according to Snodgrass \& Vanderwart, 1980); (3) between three and nine letters (inclusive); and (4) no homophones or homographs.

The set of 108 concepts was divided into three subsets of 36 each The subsets were then counterbalanced across subjects so that each one appeared equally often under each of the three priming treatments. This was achieved by establishing list organization as a between-subjects variable, with a separate arrangement for each group of 8 subjects.

An additional set of 60 concepts was selected from the same list for use in the second part of the experiment. As these items were presented in word form only, for practice and parameter estimation, the second of the above requirements was relaxed.

The line drawings and words were prepared on separate cards for presentation in the first phase of the experiment. The line draw- ings were copied from the Snodgrass and Vanderwart (1980) set. The words were typed in uppercase letters.

In the parameter estimation and test phases of the experiment, the words were presented on a Tektronix 620 Cathode Ray Oscilloscope. Each word appeared in uppercase letters, subtended approximately $1^{\circ}-3^{\circ}$ on the horizontal axis, and remained on display for a duration determined by parameter estimation. The letters were drawn from the Horatio Light character set, and consisted of between 30 and 165 points.

Each word was followed by a pattern mask for $50 \mathrm{msec}$. The mask consisted of 52 letter fragments ( 2 fragments per letter and 20 points per fragment) and occupied a variable region on the oscilloscope determined by the height and length of the to-be-masked word.

Subjects. Thirty-three undergraduate students between 19 and 35 years of age participated in a single experimental session lasting approximately $30 \mathrm{~min}$. Nine subjects were rejected because their accuracy values in the new word treatment in the test phase of the experiment indicated that the PEST-derived SOA was unsuitable. In these cases accuracy was either greater than $75 \%$ or less than $25 \%$ correct, values unlikely to occur by chance (alpha $=.05$ ), given 36 observations and an expected mean of $50 \%$.

\section{Results}

The mean SOA for the 24 subjects included in the final analysis was $14 \mathrm{msec}$, with individual values ranging from 7 to $33 \mathrm{msec}$.

The results for Experiment 1 are summarized in Table 2. Mean accuracy for the new word treatment was $46.8 \%$, a satisfactory outcome, given an expected value of $50 \%$ correct following parameter estimation. The corresponding values for the picture-word and word-word conditions were $55.3 \%$ and $61.6 \%$ correct, respectively, suggesting that intermodal as well as intramodal facilitation was present. The RP value for these data is 0.57 .

Although the experiment did not include a control for display method (the study and test words were presented in the same font, but on cards and on a cathode ray oscilloscope, respectively), a comparison between the results of Experiment 1 and, for example, the equivalent frequency conditions from Kirsner, Milech, and Standen (1983, Experiments 4-6) indicates that RP is relatively or even absolutely insensitive to this change in stimulus class. Comparable results have been obtained under case-

Table 2

Word Identification (Percent Correct) as a Function of Experiment, Encoding Treatment, Repetition Treatment, and Word Frequency

\begin{tabular}{|c|c|c|c|c|c|c|}
\hline \multirow[b]{2}{*}{ Experiment } & \multirow{2}{*}{$\begin{array}{l}\text { Encoding } \\
\text { Treatment }\end{array}$} & \multirow{2}{*}{$\begin{array}{l}\text { Word } \\
\text { Frequency }\end{array}$} & \multicolumn{3}{|c|}{$\begin{array}{l}\text { Repetition Treatment } \\
\text { (Absolute Values) }\end{array}$} & \multirow[b]{2}{*}{$\mathbf{R P}$} \\
\hline & & & NW & PW & $\mathbf{w W}$ & \\
\hline 1 & $\begin{array}{c}\text { Semantic } \\
\text { Classification }\end{array}$ & & 46.8 & 55.3 & 61.6 & .57 \\
\hline 2 & $\begin{array}{c}\text { Naming } \\
\text { Size Judgment }\end{array}$ & & $\begin{array}{l}51.4 \\
50.2\end{array}$ & $\begin{array}{l}63.1 \\
59.0\end{array}$ & & \\
\hline 3 & Naming & $\begin{array}{l}\text { Low } \\
\text { High }\end{array}$ & $\begin{array}{l}43.6 \\
44.7\end{array}$ & $\begin{array}{l}65.3 \\
56.7\end{array}$ & & \\
\hline 4 & Naming & $\begin{array}{l}\text { Low } \\
\text { High }\end{array}$ & & $\begin{array}{l}44.0 \\
47.2 \\
\end{array}$ & $\begin{array}{l}54.8 \\
57.5 \\
\end{array}$ & $\begin{array}{l}.67 \\
.54 \\
\end{array}$ \\
\hline
\end{tabular}

Note $-W W=$ word-word; $P W=$ picture-word NW $=$ new word; $\mathrm{RP}=$ relative priming (values shown for Experiment 1 and for Experiments 3 and 4 in combination). 
change and font-change conditions (Morton, 1979; Scarborough et al., 1977).

A one-way analysis of variance showed that the main effect of repetition status was significant $[F(2,46)=18.6$, $p<.01]$. Comparisons conducted according to NewmanKeuls showed that the differences between the word-word and new word conditions and between the picture-word and new word conditions were significant at alpha $=.01$. The difference between the word-word and picture-word conditions was also significant at alpha $=.01$.

\section{Discussion}

The first experiment was conducted to assess whether pictorial presentation of a concept can facilitate performance when the concept is subsequently presented again, as a word, for naming. The results were clear. Significant facilitation occurred under picture-word transfer conditions. Furthermore, although the mean RP value for the group of subjects as a whole $(0.57)$ is greater than that calculated for the five naming experiments $(0.39)$ and for the entire set of nine picture-word transfer studies (0.35) in Table 1 , it does not fall outside the range of values for those studies.

The main points to emerge from the present analysis are as follows. First, provided that appropriate test procedures are used, significant repetition priming may be observed under picture-word conditions. Second, when it is expressed in proportional terms, our result is not, in fact, exceptional. Indeed, it conforms to the pattern of previous research. Third, the proposition that repetition transfer between pictures and words is restricted to the word-picture condition should be discarded.

When the comparison is extended to intermodality transfer, a measure of agreement is also apparent. As summarized above, the mean RP values for transfer under printspeech and speech-print conditions were 0.48 and 0.42 , respectively, and the claim that all of these values reflect the operation of a single stage or set of processes is at least tenable. There is, moreover, a sharp distinction between these values and those that are observed between translations (where RP approaches zero), on the one hand, and intramodality variations (where RP approaches unity), on the other. It is apparent, then, that although there is much variability within each data set, the overall RP levels are similar under each of the four mode and modality combinations, and that this is not a general property of the paradigm.

\section{EXPERIMENT 2}

Experiment 2 was conducted to examine the replicability and stability of transfer between pictures and printed words. The impetus for the chosen manipulation comes from Durso and Johnson's (1980) finding that memory for mode-a subject's ability to decide whether a concept has been presented previously as a word or picture-is particularly sensitive to encoding strategy. They found that when subjects encoded visual words and pictures by making referential size judgments, they confused presentation mode on a subsequent test more than did subjects who encoded by naming. The implication for our purposes is that judgments about the size of concepts increased the likelihood of transfer between the pictorial and verbal modes.

One of the assumptions in the model we presented in the introduction is that a common set of processes is involved in the identification of printed words, spoken words, and pictures. Central to this assumption is that these are primary processes, that is, processes that are necessary for identification, but irrelevant to the establishment of elaborate episodic representations. These representations are attributed to secondary processes, such as those investigated by Durso and Johnson (1980) and Craik and Tulving (1975). If the distinction between primary and secondary processes is correct, repetition transfer under picture-word conditions should be insensitive to encoding strategy. But if the distinction is invalid, repetition transfer should be sensitive to variables that influence memory for stimulus class.

\section{Method}

The design, procedure, stimulus selection, and subject selection followed those of the first experiment, with the following exceptions. First, only the new word and picture-word conditions were tested. It should be noted that it was the equivalent picture-word condition that showed the biggest increase in confusion errors in Durso and Johnson's (1980) study, and that this is therefore the transfer condition which is most likely to be sensitive to strategy. Second, because the same set of 108 items was used in Experiments 1 and 2 , there were 54 instead of 36 items per treatment. Third, the study phase involved either naming (Group 1) or referential size judgment (Group 2). Subjects in the naming group were required to name each object. Subjects in the referential size judgment group were instructed to rate the size of the real-world object on a 7-point scale.

There were 12 subjects in each group.

\section{Results}

The results, summarized in Table 2 , show clear facilitation under picture-word conditions for both groups, and therefore confirm our claim that repetition transfer occurs under these conditions. Comparison between the groups indicates that, if anything, facilitation was greater after naming than after referential size judgment, but the group difference is small relative to the priming effect.

An analysis of variance supported this summary, showing a significant effect of repetition status $[F(1,22)=30.1$, $p<.01]$ but no suggestion of a significant main effect or interaction involving encoding strategy $(F<1$ in each case).

The results complement those of Experiment 1, showing transfer under picture-word conditions, and indicate that repetition transfer is insensitive to at least the present manipulation of elective processes, a characteristic that is to be expected if repetition priming reflects "priming processing." 


\section{EXPERIMENTS 3 AND 4}

Experiments 3 and 4 were designed to evaluate the proposition that the intra- and intermodal components identified in the first two experiments reflect the operation of distinct processes. In essence, these experiments constitute an extension of a procedure previously applied to the relationship between spoken and written language (Kirsner et al., 1983, Experiments 7 and 8). In the earlier experiments, we found that the additional priming contingent on the use of low-frequency words (Scarborough et al., 1977) was restricted to the intermodality component. That is, with new visual words as the control, and identification of low- and high-frequency items equated by PEST, the magnitude of facilitation observed for auditorily primed words (intermodality priming) was greater for the low-frequency set than for the high-frequency set. However, when the auditorily primed words were used as the control, the additional facilitation attendant on visual priming (intramodality priming) was virtually identical for low- and high-frequency words.

The theoretical rationale for extending this analysis to intermodal repetition transfer involves two assumptions. The first assumption is that, where general conceptual analysis is concerned, the same processes are involved in the identification of spoken words, printed words, and pictures. This assumption provides for the co-occurrence of both mode- and modality-specific effects and modeand modality-independent effects in word identification, but it associates the latter with more abstract processing levels. The second assumption is that word frequency selectively influences the common and more abstract level. If these assumptions are correct, it follows that, as in priming from spoken to printed words, frequency will have its impact on the intermodal component-from pictures to words-and that the additional facilitation observed under intramodal conditions will not vary with word frequency.

\section{Method}

Design. The design for Experiments 3 and 4 involved two factors, repetition status and word frequency, with repeated measures on each factor. There were two repetition status treatments--the new word condition and the picture-word condition in Experiment 3 and the picture-word and word-word conditions in Experiment 4and two frequency treatments, involving high- and low-frequency words.

Procedure. Experiment 3 consisted of three phases. The first was a study phase in which subjects named 25 low-frequency and 25 high-frequency concepts, all of which were depicted as line drawings.

In the second phase, we used PEST with visually presented words to establish separate identification thresholds for the high- and lowfrequency conditions. The items used in this phase were all new (i.e., had not been used in the first phase), but they were matched with the critical sets in regard to frequency, concreteness, and, to a lesser extent, pictorial ease of naming.

The third phase consisted of an additional 100 word identification trials, 25 from each combination of the repetition (new word vs. picture-word in Experiment 3, and picture-word and word- word in Experiment 4) and frequency (high vs. low) variables. Each item in this phase was presented at its frequency-specific SOA, which had been calculated at the end of the second phase. Two formats were used so that items included in the picture-word treatment for 8 subjects were included in the new word treatment for the remaining subjects, and vice versa.

Experiment 4 was identical to Experiment 3 except that (1) all of the items to be used for parameter estimation were included, as line drawings, in Phase 1, and (2) instead of comparing the new word and picture-word conditions, the experiment compared the picture-word and word-word conditions. To achieve this comparison, all of the available items were presented in Phase $1 ; 120(60$ per frequency level) were presented as line drawings for subsequent use in the second, parameter estimation, phase: 50 ( 25 per level) were presented as line drawings for subsequent use as test words under picture-word conditions in Phase 3; and 50 (25 per level) were presented as words for subsequent use as test words under word-word conditions in Phase 3. Two formats were also used in Experiment 4, so that each item appeared equally often in each repetition condition.

Stimulus selection. Stimulus selection followed that of Experiments 1 and 2, except that a number of additional items were selected and prepared in order to provide separate high- and low-frequency subsets. These stimuli were selected and drawn to be compatible with those described by Snodgrass and Vanderwart (1980). Altogether, 50 items per frequency level were available in each subset; another 60 items (per frequency level) were regarded as suitable for parameter estimation (when used as words), although less reliable for pictorial naming purposes. The mean Kucera and Francis (1967) frequency values were 111 (range $=41-591$ ) and 4 (range $=0-10$ ) for the critical high- and low-frequency items, respectively.

The crucial items in each frequency band were allocated systematically to each subset so that each new word and picture-word (Experiment 3) or picture-word and word-word (Experiment 4) treatment involved presentation of frequency-matched items for each subject. Within each frequency level, the word subsets and repetition treatments were counterbalanced, so that each item was presented in each condition for 8 subjects.

Subjects. Subject selection followed that of Experiment 1, but with 8 subjects per format, and two formats per experiment.

\section{Results}

The results from Experiments 3 and 4 are summarized in Table 2. As shown in the table, there is a clear interaction between frequency and repetition status in Experiment 3, but not in Experiment 4. The form of the interaction is similar to that observed previously for spoken and written words: a greater priming benefit is associated with low-frequency words only in the intermodal condition. High- and low-frequency items receive comparable benefit from intramodal priming.

An analysis of variance conducted on the results of Experiment 3 demonstrated that the main effect of repetition status $[F(1,15)=37.4, p<.01]$ and the interaction between word frequency and repetition status $[F(1,15)=$ $8.0, p<.05]$ were both significant. The main effect of frequency was not significant $(F<1)$.

In a comparable analysis conducted on the results of Experiment 4 , only the main effect of repetition status $[F(1,15)=22.3, p<.01]$ was significant. The main effect of frequency $(F<1)$ and the interaction between the variables $(F<1)$ were not significant. 
Because the words used in the second, parameter estimation, phases of the experiments were either new (Experiment 3 ) or old (having previously been presented in line drawing form; Experiment 4), the PEST-derived threshold values provide the basis for a supplementary test of transfer under picture-word conditions. The threshold data are consistent with the accuracy data. Much as it had improved accuracy at a given threshold in the first two experiments, prior experience with pictures had the effect of reducing the PEST-derived threshold solutions in Experiments 3 and 4 . The actual 50\% threshold values for Experiment 3 (new words) were $23.4 \mathrm{msec}(S D$ $=4.6)$ and $20.3 \mathrm{msec}(S D=4.3)$ for the low- and highfrequency conditions, respectively; the equivalent values for Experiment 4 (words previously seen as line drawings) were $15.4 \mathrm{msec}(S D=3.2)$ and $12.9 \mathrm{msec}$ $(S D=4.3)$.

The picture-naming accuracy values were in excess of 99\% correct in each condition.

\section{EXPERIMENT 5}

Experiment 5 was designed to contrast the effects of stimulus class on perceptual identification and episodic recognition. Following Scarborough, Gerard, and Cortese (1979), it was expected that episodic recognition would be superior under picture-word conditions, a reversal of the pattern observed under word identification conditions in the first four experiments. In their study, Scarborough et al. (1979, Experiment 3) presented pictures and words during a study phase involving lexical decision, and subsequently asked subjects to make old/new judgments to test words in an incidental test of episodic recognition. Despite possible ambiguity in picture-to-word correspondence, subjects were superior in regard to speed and accuracy following pictorial exposure. Given the discrepancy between the results of the repetition priming experiments reported here and those reported by Scarborough et al. (1979, Experiments 1 and 2), we designed the fifth experiment as a replication of their episodic experiment.

The reported disadvantage for same-mode conditions is of particular interest because, when the repetition priming and episodic recognition results are considered together, they constitute a "crossover interaction," according to Tulving's (1983) usage of that term. Although the word-word condition is superior to the picture-word condition under repetition priming conditions, it is inferior under episodic recognition conditions. The implications of this pattern of results will be considered in the General Discussion.

\footnotetext{
Method

Design. The design involved two factors, repetition status and word frequency, with repeated measures on each factor. There were three repetition status treatments-the new word condition, the picture-word condition, and the word-word condition-and two frequency treatments, involving high- and low-frequency words.
}

Procedure. The experiment was conducted in two phases. In the first phase, the subjects were presented with 100 concepts-25 under each of the four conditions given by the factorial combination of stimulus class (pictures or words) and frequency (high or low)and were instructed to name each concept. They were not informed that the concepts would be presented again later in the experiment. In the second phase, the subjects were presented with the entire set of 150 concepts -50 under each of the new word, picture-word, and word-word conditions-and were instructed to classify each stimulus as "new" or "old." The subjects were instructed to classify concepts as "old" if they had been presented in the first phase as either pictures or words.

In the first, study, phase, the pictures and words were presented on individual cards. In the second, test, phase, the words were presented on an oscilloscope, where each remained in view until the subject had responded or for $10 \mathrm{sec}$, whichever was shorter.

Stimuli. The stimulus set consisted of the 50 high-frequency and 50 low-frequency concepts used in Experiments 3 and 4, plus an additional 25 concepts from each of the frequency bands used in those experiments. Twenty-five stimuli from each frequency band were allocated to each of the three subsets, and these subsets and the repetition treatments (new word, picture-word, and word-word) were counterbalanced so that each concept was tested in each experimental treatment for 6 subjects. The mean frequency values for the low- and high-frequency sets were 4 (range $=0-10$ ) and 111 (range $=41-591$ ) per million, respectively

Subjects. Eighteen undergraduate students between 18 and 40 years of age participated in a single experimental session lasting approximately $30 \mathrm{~min}$.

\section{Results}

Performance on the picture-naming task was very reliable. The mean accuracy values for the low- and highfrequency conditions were $99.1 \%$ and $98.9 \%$ correct, respectively.

The episodic-recognition results from the second phase of the experiment are shown in Table 3. As expected, performance was better in the picture-word conditions than in the word-word conditions. Averaged over high- and low-frequency concepts, the mean accuracy and reaction time advantages for the picture-word condition were $48.1 \%$ and $0.30 \mathrm{sec}$, respectively.

An analysis of variance conducted on the accuracy data from the two old conditions indicated that the main effect of repetition status $[F(1,17)=278, p<.01]$ and the main effect of word frequency $[F(1,17)=14.7$, $p<.01]$ were both significant, but the interaction between these variables was not significant. In an equiva-

Table 3

Experiment 5: Episodic Recognition Accuracy (Percent Correct) and Reaction Time (in Seconds) as a Function of Repetition Treatment and Word Frequency

\begin{tabular}{|c|c|c|c|c|}
\hline \multirow{2}{*}{$\begin{array}{c}\text { Word } \\
\text { Frequency }\end{array}$} & \multirow{2}{*}{$\begin{array}{c}\text { Dependent } \\
\text { Variable }\end{array}$} & \multicolumn{3}{|c|}{$\begin{array}{c}\text { Repetition Treatment } \\
\text { (Absolute Values) }\end{array}$} \\
\hline & & NW & PW & WW \\
\hline $\begin{array}{l}\text { Low } \\
\text { High }\end{array}$ & $\begin{array}{l}\text { Accuracy } \\
\text { Accuracy }\end{array}$ & $\begin{array}{l}89.6 \\
87.8\end{array}$ & $\begin{array}{l}85.1 \\
77.3\end{array}$ & $\begin{array}{l}38.2 \\
28.2\end{array}$ \\
\hline $\begin{array}{l}\text { Low } \\
\text { High }\end{array}$ & $\begin{array}{l}\text { Reaction time } \\
\text { Reaction time }\end{array}$ & $\begin{array}{l}1.25 \\
1.35 \\
\end{array}$ & $\begin{array}{l}0.98 \\
1.00 \\
\end{array}$ & $\begin{array}{l}1.20 \\
1.39 \\
\end{array}$ \\
\hline
\end{tabular}

$\overline{\text { Note}}-\mathrm{WW}=$ word-word $\mathrm{PW}=$ picture-word $\mathrm{NW}=$ new word. 
lent analysis conducted on the reaction time data, only the main effect of stimulus class was significant $[F(1,17)$ $=11.4, p<.01]$. The significance of these results is considered in the General Discussion.

\section{GENERAL DISCUSSION}

The major findings are as follows. First, repetition priming of words by prior pictures is found with the PEST procedure, in which the dependent variable is accuracy of word identification (Experiments 1, 2, and 3) or the identification threshold (Experiments 3 and 4). Second, the magnitude of repetition priming under intermodal conditions is less than that observed under intramodal conditions, an outcome which is consistent with the modality data (Experiments 1 and 4). Third, the magnitude of priming under intermodal conditions does not vary according to whether subjects study the initial pictures with size judgment or naming (Experiment 2). This third finding contrasts word identification with memory for mode, in which the encoding task does have an effect. Fourth, when repetition effects for low-frequency and high-frequency words are compared, when the prime is either a picture or a word, there is a frequency difference for intermodal priming, but the additional priming attributable to intramodal effects does not vary with frequency (Experiments 3 and 4). Fifth, when episodic recognition is tested, the relationship between the intra- and intermodal conditions is reversed, and the picture-word treatment is superior in regard to speed and accuracy (Experiment 5).

As our interpretation of these results is guided by a particular view of repetition priming and transfer between stimulus classes, we will develop it in that context.

\section{General Basis of Repetition Priming}

In developing an account of RP, we found it useful to distinguish between what we have termed primary processing and secondary processing. By primary processing, we mean those processes that are that are necessary to establish the identity of a stimulus. In principle, all stimulus qualities must be resolved in order to determine identity, so it follows that processes that are sensitive to, for example, case, typefont, spatial position, frequency, lexical form, and, possibly, sense will be engaged during word identification. Secondary processing, in contrast, involves processes that operate subsequent to, or apart from, stimulus identification. Secondary processing is subject to voluntary control, and different secondary processes will, of necessity, be invoked under acquisition and test conditions in multitrial experiments. For example, instructions regarding depth of processing and referential size judgment create task demands that involve secondary processing during acquisition, whereas instructions regarding episodic recognition (old/new judgments) and memory for stimulus class (same/different judgments) create task demands that involve secondary processing during testing.
The results reported here are consistent with the distinction between primary and secondary processing in two ways. First, strategy variation during the study phase, a secondary processing manipulation, has no effect on RP, although comparable manipulations have dramatic effects on memory for stimulus class (Durso \& Johnson, 1980). This result is, of course, subject to the inferential limitations associated with single dissociation. Second, when secondary processing is required during the test phase, as in Experiment 5 (old/new judgments), the advantage enjoyed by the word-word condition over the pictureword condition is reversed.

The distinction we have drawn between primary and secondary processing may be similar to that drawn by Tulving (1983) and others between procedural and declarative knowledge. However, we prefer primary processing and secondary processing in the present context, because these terms preserve the operational quality of the contrast. The argument that RP reflects the re-use of a procedural pathway is appealing, particularly given the way in which stimulus class variations influence the magnitude of RP, but the procedural appellation is not demanded by the data; priming processing could reflect access to declaratively structured information about recent episodes.

Some qualifications are required. The first of these concerns generation effects (Posner, 1975), which make it necessary to assume that primary processing can be initiated subsequent to initial stimulus identification, for example, by a deliberate decision to imagine an alternative form of the presented stimulus. When generation has been examined in relation to repetition priming between translations (Kirsner et al., 1984, Experiment 2), the results have suggested that generation yields effects that are not readily distinguished from normal stimulus identification, as has been shown for a variety of perceptual tasks (e.g., Farah, 1985; Finke, 1980; Podgorny \& Shepard, 1978). The second qualification concerns the possibility that secondary processing is, like primary processing, sensitive to the relationship between study and test conditions (Tulving, 1983), except that in this case secondary processing can be expected to reflect the extent to which the same secondary processes are invoked during study and test. Thus, if it is assumed that context selectively influences secondary processing, it follows that performance on episodic-recognition tasks will be sensitive to manipulation of this variable (Fisher \& Craik, 1980), whereas RP on stimulus-identification tasks will not (Stumpfel \& Kirsner, in preparation). It may be noted, however, that this dissociation depends on the assumption that performance in word identification depends $e x$ clusively on primary processing, an assumption that may be unnecessarily restrictive. The third qualification concerns the use of primary processing products in secondary processing, a circumstance in which the latter may be sensitive to the quality of the former, in terms of perceptual fluency, for example (Johnston, Dark, \& Jacoby, 1985). 


\section{Basis of Transfer Between Stimulus Classes}

The argument in this section is developed in three phases, involving (1) the interpretation of relative priming, (2) the possibility that a common stage or set of processes is involved in transfer between the various mode and modality combinations, and (3) RP variability.

RP may be interpreted in two ways, reflecting weak and strong assumptions about its basis. According to the weak assumption, a given RP value reflects the proportion of primary processes that are common to the study and test stimulus analyses. Thus, if it is accepted that the "real" RP values for transfer from spoken to printed words and from pictures to printed words are each 0.50 , for example, it may be inferred that $50 \%$ of the processes determining the variance in RP are common to both combinations. But the position in regard to the constituent members of each of the subsets is open. They may or may not be the same in each case. According to the strong assumption, however, the same subset of processes is involved in each combination. Those processes that belong to the intersection between spoken and printed words also belong to the intersection between pictures and printed words, and, by extension, to the intersection between spoken words and pictures.

But just how plausible is the strong assumption? There are several reasons for suspecting that it is not plausible at all. First, where sense or nuance is concerned, it may be reasonable to assume that more or less the same interpretation is achieved following spoken and printed presentation of an isolated word, but this appears to be much less likely when pictures and printed words are presented. The sense derived from a picture or line drawing may be more or less abstract, depending on usage (Kolers \& Brison, 1984), but there is no basis for assuming that the senses derived from the two forms will be equivalent. Second, although lexical form is specified for spoken and printed words, this is not the case for isolated pictures, and pictures and words are therefore not equivalent in this respect. Third, in the absence of morphological specification, it is impossible to determine frequency of occurrence for pictorial forms, even if this were a meaningful concept where line drawings are concerned. Yet we know that both cluster frequency and particular form frequency are important determinants of performance (Bradley, 1979; Taft, in press). For these reasons, then, the strong assumption cannot be adopted as the default option, and it is necessary to adopt a weaker position. One possibility, midway between the weak and strong positions outlined above, is that RP reflects the operation of a large set of processes, and that the impact of frequency on intermodal and intermodality transfer reflects the selective influence of just one of these processes. In this account, then, it is not assumed that the entire set of processes is the same in each case, only that one process is common to the intersection between the processes involved in the analysis of printed words, spoken words, and pictures, and that this process is sensitive to frequency.
However, as Kolers and Brison (1984) implied, there is a qualitative step from (in spoken or printed form) to pictures (in any form), and the equivalence of the RP values obtained under intermodal and intermodality conditions requires explanation. If the two stimulus classes are so different, why are the observed RP values so similar? If totally different processes were involved in word and picture processing, the obtained RP values for mode and modality should be quite different. Despite their disenchantment with experiments that treat words and pictures as in any way equivalent, Kolers and Brison provided a clue to the answer, as well as the question.

Consider the following specific assumptions about RP: first, that it ranges from unity, when the study and test stimuli are morphologically identical, to zero, when the study and test stimuli are morphologically unrelated (Cristoffanini et al., in press; Downie, Milech, \& Kirsner, 1985; Kirsner, 1986); second, that the set of effective morphological dimensions reflects syntactic, inflective, derivational, and other lexical properties; third, that for a given morphological relationship, each change in stimulus class exerts a further "cost" in RP terms; fourth, that the set of effective stimulus class dimensions includes mode, modality, and a range of nested intramode and intramodality properties (e.g., fundamental frequency, stress, accent, and spatial location for spoken words), although it may be suggested that mode and modality exist only as composites of the nested dimensions.

On the face of it, this summary of our views provides a clear basis for predicting that RP should be equal to zero where transfer between pictures and words is concerned. But, clearly, it is not. The answer, we propose, lies in Kolers and Brison's (1984, p. 108) claim that it is the way in which pictures are taken and used that is important, not the way in which they can be described as physical objects. If the task demands encourage people to invoke processes that reflect word structure, then that is what people will do, even when no alphabetic information is present. In our experiments on mode and modality, it is clear that the pictorial as well as alphabetic depictions served a linguistic function, and the RP values reflect this.

Perhaps the weakest link in our analysis involves the observed variability in RP. We know of no studies designed specifically to examine this variability at the intra-individual level, which is the critical level where process analysis is concerned (Brown \& Kirsner, 1980), but the magnitude of the variability between experiments and between experimenters is evident in the meta-analyses summarized in the introduction.

Two factors that may contribute to RP variability are word sense or nuance (Jastrzembski, 1981) and function. The sense argument applies to both modality and mode, but it is likely to be more important when pictorial or line drawing presentation is included. The proposition is, in brief, that repetition priming is sense-specific, and that sense dominance is mode- and, to a lesser extent, modality-specific. When the same sense is accessed or constructed during the study and test phases, RP will be 
complete; when a different sense is involved, RP will be reduced or absent. As a further refinement of this position, it could be argued that there is a continuum on which $\mathrm{RP}$ increases as a function of increasing similarity between the study and test senses. This continuum would, logically, parallel that which we have observed for morphology (Cristoffanini et al., in press; Kirsner, 1986), although the former might succeed the latter in processing terms. The importance of sense in RP has not been firmly established, but is suggested by findings showing that RP is reduced when words are selectively embedded in discourse during the study phase (Oliphant, 1984) and by evidence that induction of different homographic interpretations during the study and test presentations eliminates repetition priming (Masson \& Freedman, 1985).

The functional argument is a natural extension of Kolers and Brison's (1984) position. Insofar as contextual, instructive, or subjective factors yield variation in the extent to which subjects treat pictures as linguistic objects, $R P$ variation is to be expected.

\section{CONCLUSION}

The most important result from the series of experiments reported here is that repetition priming is observed when a test word is preceded by a line drawing of the same concept. This outcome is inconsistent with several accounts of the relationship between word and picture identification processes (e.g., Durso \& Johnson, 1979; Morton, 1984). The result was replicated, and we demonstrated (1) that transfer between line drawings and printed words in picture-word conditions may be insensitive to strategy manipulations during the study phase, and (2) that, as with transfer from spoken words to printed words, word frequency selectively influences the intermodal component.

In considering the implications of these results, however, we have adopted a conservative position in a number of respects. First, rather than assume that the apparent equivalence of the intermodal and intermodality RP values reflects the involvement of a common set of processes, we assume that their equivalence reflects the involvement of a similar proportion of the processes involved, and argue that the selective frequency effect implies only that one of these processes is involved in both intermodal and intermodality transfer. The other processes that are common to the identification of spoken and printed words may or may not be the same processes as those that are common to word and picture identification. Second, rather than assume that we have an estimate of the "true" value of RP for transfer between pictures and words, we are inclined to the view that we have determined an estimate of the RP value that applies only when pictures are treated as linguistic objects. We accept the possibility, then, that when pictures are treated as pictures, RP will be reduced or eliminated.

Finally, we suggest that the influence of sense (nuance) and function on RP is an artifact of mismatching between the scale of the representations formed and tested during the study and test phases of experimentation. When single words are presented and tested, their status as linguistic objects is clear, and interpretation is likely to be restricted to their dominant or citation senses during both the study and the test phase of the experiment. But when words are presented in discourse during the study phase and then are tested in isolation, qualitatively different sets of processes may be invoked on the two occasions.

The story for pictures may not be so very different, particularly if the notion of a mental model (Johnson-Laird, 1983) is invoked to account for both discourse and event comprehension. When a single picture or line drawing is presented, linguistic treatment is likely, and the object file formed following identification and interpretation will be amenable to repetition priming when a test word is presented. But when pictures of objects are embedded in a scene, pictorial treatment is likely, and RP should therefore be absent when key concepts are tested as words. (As an illustration, consider a scene in which a burglar opens a safe with a set of skeleton keys, following which the word $\backslash$ KEYS $\backslash$ is presented as a test stimulus.)

The final question of interest, then, concerns the media specificity of mental models formed during discourse and scene comprehension. If these are truly amodal, and are dominated by the structure of the real or actual event, it follows that RP will approach unity, provided only that the test sentences and scenes are equivalent depictions of the event.

\section{REFERENCES}

BRADLEY, D. (1979). Lexical representation of derivational relations. In M. Aranoff \& M. L. Kean (Eds.), Juncture. Cambridge, MA: MIT Press.

Brown, H. L., \& KIRSNER, K. (1980). A within-subjects analysis of the relationship between memory span and processing rate in shortterm memory. Cognitive Psychology, 12, 177-187.

Clarke, R., \& Morton, J. (1983). Cross-modality facilitation in tachistoscopic word recognition. Quarterly Journal of Experimental Psychology, 35A, 79-96.

Craik, F. I. M., Tulving, E. (1975). Depth of processing and the retention of words in episodic memory. Journal of Experimental Psychology: General, 104, 269-294.

Cristoffanini, P. M., Kirsner, K., \& Milech, D. (in press). Bilingual lexical representation: The status of cognates. Quarterly Journal of Experimental Psychology.

Dannenbring, G. L., \& Briand, K. (1982). Semantic priming and the word repetition effect in a lexical decision task. Canadian Journal of Psychology, 36, 435-444.

Downie, R., Milech, D., \& Kirsner, K. (1985). Unit definition in the mental lexicon. Australian Journal of Psychology, 37, 141-155.

Durso, F. T., Johnson, M. K. (1979). Facilitation in naming and categorizing repeated pictures and words. Journal of Experimental Psychology: Human Learning \& Memory, 5, 449-459.

Durso, F. T., \& Johnson, M. K. (1980). The effects of orienting tasks on recognition, recall, and modality confusion of pictures and words. Journal of Verbal Learning and Verbal Behavior, 19, 416-429.

Durso, F. T., O'Sullivan, C. S. (1983). Naming and remembering proper and common nouns and pictures. Joumal of Experimental Psychology: Learning, Memory \& Cognition, 9, 497-510.

Farah, M. J. (1985). Psychophysical evidence for shared representational medium for mental images and percepts. Joumal of Experimental Psychology: General, 114, 91-103. 
FINKE, R. A. (1980). Levels of equivalence in imagery and perception. Psychological Review, 87, 113-132.

Fisher, R. P., Craik, F. I. M. (1980). The effects of elaboration on recognition memory. Memory \& Cognition, 8, 400-404.

Gough, P. B., Alford, J. A., \& Holley-Wilcox, P. (1981). Words and contexts. In O. J. L. Tzeng \& H. Singer (Eds.), Perception of print. Hillsdale, NJ: Erlbaum.

Henderson, L., Wallis, J., \& KNIGH', D. (1984). Morphemic structure and lexical access. In H. Bouma \& D. Bouhuis (Eds.), Attention and performance $X$. Hillsdale, $\mathrm{NJ}$ : Erlbaum.

Hunter, J.E., SChMidt, F. L., JACKSON, G. B. (1982). Advanced meta-analysis: Quantitative methods for cumulating research findings across studies. San Francisco: Sage.

JACKSON, A., MORTON, J. (1984). Facilitation in auditory word recognition. Memory \& Cognition, 12, 568-574.

JACOBY, L. L., Dallas, M. (1981). On the relationship between autobiographical memory and perceptual learning. Journal of Experimental Psychology, 110, 306-340.

JaSTRZEMBSKı, J. E. (1981). Multiple meanings, frequency of occurrences, and the lexicon. Cognitive Psychology, 13, 278-305.

Johnson-LAIRD, P. N. (1983). Mental models. Cambridge: Cambridge University Press.

Johnston, W. A., DARK, V. J., \& JACOBY, L. L. (1985). Perceptual fluency and recognition judgments. Journal of Experimental Psychology: Learning, Memory \& Cognition, 11, 3-11.

Jolicoeur, P., Gluck, M. A., Kosslyn, S. M. (1984). Pictures and names: Making the connection. Cognitive Psychology, 16, 243-275.

KIRSNER, K. (1986). Lexical representation: Is a bilingual account necessary? In J. Vaid (Ed.), Language processes in bilinguals: Psycholinguistic and neuropsychological perspectives. Hillsdale, NJ: Erlbaum.

Kirsner, K., Brown, H. L., Abrol, S., Chaddha, N. N., \& Sharma, N. K. (1980). Bilingualism and lexical representation. Quarterly Journal of Experimental Psychology, 4, 585-594.

KIRSNER, K., DunN, J. C. (1985). The perceptual record: A common factor in repetition priming and attribute retention. In M. I. Posner \& O. S. M. Marin (Eds.), Mechanisms of attention: Attention and performance $X I$. Hillsdale, NJ: Erlbaum.

Kirsner, K., Milech, D., Standen, P. (1983). Common and modality-specific units in the mental lexicon. Memory \& Cognition, 11, 621-630.

KIRSNER, K., \& SMITH, M. C. (1974). Modality effects in word identification. Memory \& Cognition, 2, 637-640

KiRSNeR, K., SMtTh, M. C., Lockhart, R. S., King, M.-L., \& JAIN, M. (1984). The bilingual lexicon: Language-specific units in an integrated network. Joumal of Verbal Learning \& Verbal Behavior, 23, 519-539.

Kolers, P. A., \& Brison, S. J. (1984). Commentary: On pictures, words, and their mental representation. Journal of Verbal Learning \& Verbal Behavior, 23, 105-113.

KuČEra, H., \& Francis, W. N. (1967). Computational analysis of present-day American English. Providence, RI: Brown University Press.

LofTus, G. R., (1978). On interpretation of interactions. Memory \& Cognition, 6, 312-319.

Masson, M. E. J., Freedman, L. (1985, November). Fluency in the identification of repeated words. Paper presented at the meeting of The Psychonomic Society, Boston.

MEYER, D. E., \& RUDDY, M. E. (1974, April). Bilingual word recognition: Organization and retrieval of alternative lexical codes. Paper presented at the meeting of the Eastern Psychological Association, Philadelphia.

Meyer, D. E., \& SChVaneveldt, R. W. (1971). Facilitation in recognizing pairs of words: Evidence of dependence between retrieval operations. Journal of Experimental Psychology, 90, 227-234.

MoNSELL, S. (1985). Repetition and the lexicon. In A. W. Ellis (Ed.), Progress in the psychology of language (Vol. 1). London: Erlbaum.

MorTON, J. (1979). Facilitation in word recognition: Experiments causing change in the logogen model. In P. A. Kolers, M. E. Wrolstad, \& H. Bouma (Eds.), Processing of visible language. New York: Plenum Press.

MorTon, J. (1984). Naming. In S. K. Newman \& R. Epstein (Eds.), Current perspectives in dysphasia. Edimburgh: Churchill Livingstone.

OupHaNt, G. W. (1984). Repetition and recency effects in word recognition. Australian Joumal of Psychology, 35, 393-404.

PENTLAND, A. (1980). Maximum likelihood estimation: The best PEST. Perception \& Psychophysics, 28, 377-379.

Perecman, E. (1984). Spontaneous translation and language mixing in polyglotaphasia. Brain \& Language, 23, 43-63.

Podgorny, P., \& ShePard, R. N. (1978). Functional representations common to visual perception and imagination. Journal of Experimental Psychology: Human Perception \& Performance, 4, 21-35.

Scarborough, D. L., Cortese, C., \& Scarborough, H. S. (1977). Frequency and repetition effects in lexical memory. Journal of Experimental Psychology: Human Perception \& Performance, 3, 1-17.

Scarborough, D. L., Gerard, L., \& Cortese, C. (1979). Accessing lexical memory: The transfer of word repetition effects across task and modality. Memory \& Cognition, 7, 3-12.

Scarborough, D. L., Gerard, L., \& Cortese, C. (1984). Independence of lexical access in bilingual word recognition. Joumal of Verbal Learning \& Verbal Behavior, 23, 84-99.

SNOdGRass, J. G., \& VANDERWART, M. A. (1980). A standardized set of 260 pictures: Norms for name agreements, image agreements, familiarity, and visual complexity. Journal of Experimental Psychol ogy: Human Learning \& Memory, 6, 174-215.

STUMPFEL, V., KIRSNER, K. (in preparation). Context effects in word identification and episodic recognition.

Swinney, D. A., Onifer, W., Prather, P., \& Hirshkowitz, M. (1979). Semantic facilitation across sensory modalities in the processing of individual words and sentences. Memory \& Cognition, 7, 159-165.

TAFT, M. (in press). The decoding of words in lexical access: A review of the morphographic approach. In D. Besner, T. G. Walker, \& G.E. McKinnon (Eds.), Reading research: Advances in theory and practice (Vol. 5). New York: Academic Press.

Tulving, E. (1983). Elements of episodic memory. Oxford: Clarendon Press.

Tulving, E. Schacter, D. L., \& Stark, H. A. (1982). Priming effects in word-fragment completion are independent of recognition memory. Journal of Experimental Psychology: Learning, Memory \& Cognition, 8, 336-342.

VANDERwart, M. (1984). Priming by pictures in lexical decision. Journal of Verbal Learning \& Verbal Behavior, 23, 67-83.

WARREN, C., \& MORTON, J. (1982). The effects of priming on picture recognition. British Journal of Psychology, 73, 117-129.

WinNiCK, W. A., \& Daniel, S. A. (1970). Two kinds of response priming in tachistoscopic recognition. Journal of Experimental Psychol ogy, 84, 74-81.

(Manuscript received February 28, 1985; revision accepted for publication December 23, 1985.) 